\title{
Near-Peer Tutor: A Solution For Quality Medical Education in Faculty Constraint Setting
}

\author{
Meenakshi Khapre ${ }^{1}$, Rupinder Deol ${ }^{2}$, Anusha Sharma ${ }^{3}$, Dinesh Badyal ${ }^{4}$ \\ 1. Social Preventive Medicine, All India Institute of Medical Sciences, Rishikesh, IND 2. College of Nursing, All India \\ Institute of Medical Sciences, Rishikesh, IND 3. Community and Family Medicine, All India Institute of Medical \\ Sciences, Rishikesh, IND 4. Pharmacology, Christian Medical College, Ludhiana, IND
}

Corresponding author: Rupinder Deol, deolrains@gmail.com

\begin{abstract}
Near-peer mentoring is a formal relationship in which more qualified students guide immediate junior students. It is an innovative approach to increase students' engagement from varied backgrounds and cultures in the health profession. This systematic review and meta-analysis aimed to investigate and compare the effectiveness of near-peer tutoring and faculty/expert teaching in health science undergraduates on knowledge and skill outcome. The review question considered was "how effective is nearpeer tutor compare to faculty/expert teaching for undergraduate health science students?" A comprehensive systematic search was undertaken in PubMed, Embase, Scopus, and Cochrane and screened initially in Rayyan software (Qatar Computing Research Institute, Qatar). Identified articles were screened independently for eligibility by two reviewers and extracted the data. Data were analyzed using standardized mean difference with Review manager version 5.5 (Cochrane Campbell Collaboration).
\end{abstract}

Sixteen studies were analyzed. Heterogeneity $\left(\mathrm{I}^{2}\right)$ among studies was high in knowledge and skill scores. Heterogeneity was reduced by 30-40\% after sensitivity analysis. No difference in knowledge and skill score was found among the near-peer and expert teaching groups. Students had a satisfactory learning experience with near-peer tutors except for some issues related to teaching proficiency in near-peers. Near-peer teaching was found to be as effective as faculty/expert teaching. Students were more comfortable with nearpeers. As mentioned by students, some challenges were differences in teaching skills and level of knowledge among near-peers.

Review began 06/10/2021 Review ended 07/03/2021 Published 07/16/2021

() Copyright 2021 Khapre et al. This is an open access article distributed under the terms of the Creative Commons Attribution License CC-BY 4.0., which permits unrestricted use, distribution, and reproduction in any medium, provided the original author and source are credited.
Categories: Medical Education

Keywords: peer group, peer learning, health science students, knowledge, skill, satisfaction, systematic review, metaanalysis

\section{Introduction And Background}

Near-peer teaching is becoming increasingly popular in medical education [1,2]. It is a voluntary collaboration between colleagues of almost similar rank, one or more years senior to another, and common academic interests. The immediate senior may facilitate discussions, provide personal support and feedback, while the senior clinician/faculty may oversee the mentoring process [1]. Near-peer teaching is a formal relationship in which a more qualified student provides guidance and support to another student [2].

Near-peer teaching is an innovative approach to increase students' engagement from varied backgrounds and cultures in the health profession field, addressing the lack of diversity in healthcare and the shortage of teaching faculty [1]. Effective near-peer mentoring nurtures long-term professional friendships and professional collaborations between peers [3]. We echo with an author that being close to the new learner's social, professional, age level, the near-peer mentor may influence the cognitive and psychomotor learning of the new learner in a better manner [2]. Also, the new learners may feel more comfortable asking queries and talking to someone with a lesser age gap.

Near-peer is a cost-effective alternative to expert teaching as healthcare fraternities are facing a shortage of faculty tutors and mentors. Various medical and nursing councils like General Medical Council (UK), American Medical Association (US), and National Medical Commission (India) emphasize that the medically trained personnel should also be effective teachers and communicators. Near-peer tutoring may be more beneficial for the new medical entrants as new students would be less hesitant to share their difficulties with near-peers than with faculty [3]. Notwithstanding these apparent benefits, near-peer tutoring is timeconsuming. It places additional demands and responsibilities on near-peer tutors, including leadership, prioritization, and identifying and coping with their own mistakes or weaknesses. This is especially important to consider when there is high stress among medical students due to heavy load of studies [4].

Many studies related to near-peer teaching are available, but a limited sample size in them may be a reason for inability to obtain a significant difference in learning outcomes among near-peer and expert groups. A systematic review by Rees et al. compared peer teaching to faculty teaching, where peers can be from the 
same or higher academic years [5]. We included only those peers who are at a higher academic level than study participants, i.e., near-peer tutors. We consider that near-peer tutors have gone through the same learning experiences as study participants in the recent past and therefore are in a better position to guide undergraduate students.

\section{Objectives}

The present study aimed to review the studies done on the effectiveness of near-peer mentoring and compare the effectiveness of senior near-peer tutoring and faculty (expert) teaching in health science graduates in terms of knowledge and skill score. We performed the narrative synthesis on the perceived satisfaction of students due to near-peer tutoring.

\section{Research question}

The review question considered was "how effective is a near-peer tutor compared to faculty/expert teaching for undergraduate health science students regarding improvement in knowledge, skill, and satisfaction?" Other questions that we tried to address by this review were (1) what are the reported benefits of near-peer tutoring? (2) What are the reported challenges in utilizing near-peer tutoring as a formal teaching-learning (T-L) strategy in medical education.

\section{Review}

We report this systematic review following guidelines of the Preferred Reporting Items for Systematic Reviews and Meta-Analyses (PRISMA) checklist (Appendix) [6]. We conducted a systematic review from March 2020 to March 2021.

\section{Eligibility criteria}

This review encompassed a wide range of experimental and quasi-experimental study designs, but not limited to randomized controlled trials, non-randomized controlled trials, pre-post studies, and comparative observational studies. Previous meta-analyses/reviews, editorial comments, and opinion pieces were excluded. Participants included were undergraduate health professionals from medicine, dental, nursing, and physiotherapy courses. Studies that included post-graduate students were excluded. We included studies where teaching/learning session conducted by senior/junior peer tutor as given by Bulte et al. and faculty/expert were compared for an outcome like knowledge or skill with/without student or peer satisfaction [7]. We defined peer tutor as one or more years senior to the trainee on the same level of health education training comprising junior residents (senior near-peer) and students (junior near-peer). Near-peer tutors can be interns, residents, demonstrators, tutors of senior-level using any method of instruction. Studies related to peer tutoring by same level, reciprocal peer tutoring, or class-wide peer tutoring were excluded from this review. We did not exclude the studies based on methodological quality because we planned to conduct sensitivity analysis by removing low-quality studies. We excluded studies where the full articles could not be retrieved despite our best effort and studies published in a language other than English.

\section{Search strategy}

We performed a comprehensive search to identify potentially relevant published research studies. PubMed, Embase, Scopus, and Cochrane were searched for studies published until March 2021. The search strategy was defined through the principles of a systematic search, using the population, intervention, comparison, outcome (PICO) scheme. The search term included the following keywords, i.e. "peer tutor*" "peer learn*" OR "peer teach*" AND "medicine OR medical OR nursing OR 'health science' OR dental". We could not find the medical subject headings (MeSH) term for near-peer. A detailed search strategy is given in Table 1 . 


\section{Cureus}

\begin{tabular}{|c|c|}
\hline $\begin{array}{l}\text { Search } \\
\text { engine/database }\end{array}$ & Search strategy \\
\hline PubMed & $\begin{array}{l}\text { "Peer teaching"[All Fields] OR "peer learning"[All Fields] OR "peer assisted"[All Fields] OR "peer tutoring" AND } \\
\text { (Clinical Trial [ptyp] OR Controlled Clinical Trial [ptyp] OR Comparative Study[ptyp]) }\end{array}$ \\
\hline Embase & 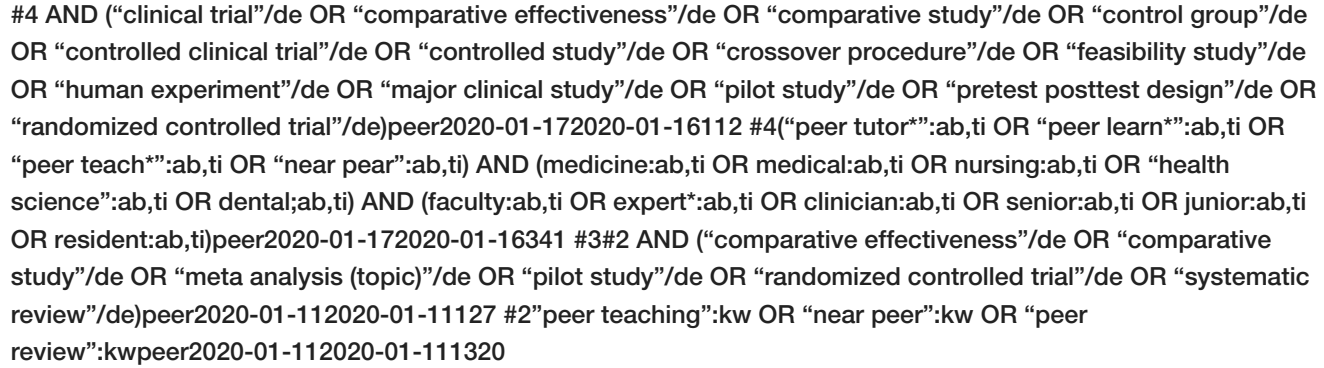 \\
\hline Cochrane & $\begin{array}{l}\text { "peer tutor*" OR "peer learn*" OR "peer teach*" in Title Abstract Keyword AND medicine OR medical OR nursing } \\
\text { OR "health science" OR dental in Title Abstract Keyword AND faculty OR expert OR clinician OR senior OR junior } \\
\text { OR resident OR doctor in Title Abstract Keyword - (Word variations have been searched) }\end{array}$ \\
\hline Scopus & $\begin{array}{l}\text { TITLE-ABS-KEY ("peer learn*" OR "peer teach*" OR "peer tutor*") AND TITLE-ABS-KEY (medical OR medicine } \\
\text { OR nursing OR "health science" OR dental) AND TITLE-ABS-KEY (expert OR faculty OR resident OR senior OR } \\
\text { junior OR doctor OR tutor OR demonstrator) AND NOT INDEX (medline) AND (LIMIT-TO (DOCTYPE, "ar")) AND } \\
\text { (LIMIT-TO (SUBJAREA, "MEDI") OR LIMIT-TO (SUBJAREA, "NURS") OR LIMIT-TO (SUBJAREA, "HEAL")) AND } \\
\text { (LIMIT-TO (LANGUAGE, "English")) }\end{array}$ \\
\hline
\end{tabular}

TABLE 1: Search strategy

\section{Study selection}

All searched result citations were loaded into and managed in Zotero bibliography software (Center for History and New Media, George Mason University, Fairfax County, VA) and duplicated articles were removed. Then it was being uploaded to Ryaan software for initial screening. After gathering the evidence, identified references were screened independently for eligibility by two reviewers using a three-stage approach with title, abstract, and full text. No stipulation was made regarding the duration or frequency of the educational program. Any type and mode of teaching-learning method were included. We resolved discrepancies during the selection process by discussion. We recorded and reported, reasons for excluding studies following the full-text review. References of included studies were hand-searched to identify any further relevant references.

\section{Data collection process}

Two trained investigators in systematic review (MK and RD) completed data extraction independently using the validated data extraction form and later compared the consensus data. Data extraction form contained information on the author, year, place of study, study design, participants characteristics (year of education and stream of health sciences), intervention (year of residency or medical education, volunteered/not volunteered), comparator group (faculty/expert clinician), teaching-learning method used, knowledge and skill pre and post-test score in both the groups (mean and SD), satisfaction score (mean and SD if available), benefits perceived and challenges encountered. Any disagreements that arose between the reviewers were arbitrated by consensus.

If the data in a study of last five years (since January 1,2014 ) were found to be unclear, missing, or presented in a non-extractable or unusable form, then we contacted the authors of studies for clarification via email and followed up after two weeks in case of no response. The authors of studies prior to January 2014 were not contacted.

\section{Data items}

Articles with variables knowledge, skill, satisfaction measured quantitatively or qualitatively were included. Benefits and challenges as perceived by students and peers were noted along with recommendations suggested by the author.

\section{Quality assessment of studies}

We assessed the methodological quality of the study using the Medical Education Research Study Quality 
Instrument (MERSQI) [8]. MERSQI and Newcastle Ottawa scale-education (NOS-E) are useful, reliable, complementary tools for appraising the methodological quality of medical education research [9]. The perfect MERSQI score was 18 . We considered more than 10.5 MERSQI scores as an acceptable quality of the study [10].

\section{Data synthesis}

We performed the narrative synthesis with a summary of included studies as a preliminary step. We then tabulated the results to identify the pattern and explain the differences in results between studies. We plotted the effect estimate in forest plot considering the standardized mean difference of knowledge and skill post-test score between expert and near-peer groups. We confirmed that the pre-test score was not significantly different in both the groups, either as reported by the author or calculated t-test or Z-score. If a significant difference was found at a baseline test score, a changed score was entered for meta-analysis. We tested the degree of heterogeneity with Cochrane $\mathrm{Q}$ and $\mathrm{I}^{2}$ statistics. We planned a sensitivity analysis considering the methodological quality if statistical heterogeneity was more than $50 \%$. We considered plotting funnel plot for publication bias only when we can include more than 10 studies in meta-analysis. The results were statistically significant when two-sided p-values were less than $5 \%$. All analyses were conducted in Review manager version 5.5 (Cochrane Campbell Collaboration).

\section{Results}

Selection of Sources of Evidence

Based on the primary search from selected databases, a total of 264 studies were identified. After removing duplicates $(n=19)$ and screening by title and abstract to remove review articles, letter to the editor, or study done on students other than health graduates, a total of 161 were eligible for full-text review. Selected articles were assessed for eligibility criteria and 145 were excluded. Among excluded studies, 58 studies had objective other than effectiveness of near-peer tutor; in 23 studies, the intervention was not peer group; in 16 studies, the comparator group does not consist of expert/faculty; and in 14 studies, the study population was other than health stream students. The meaning of peer tutor was not clear in three studies; three were review articles. The meaning of peer tutor was not clear in three studies; three were review articles. Finally, we identified 16 studies for systematic review and meta-analysis (Figure 1). 


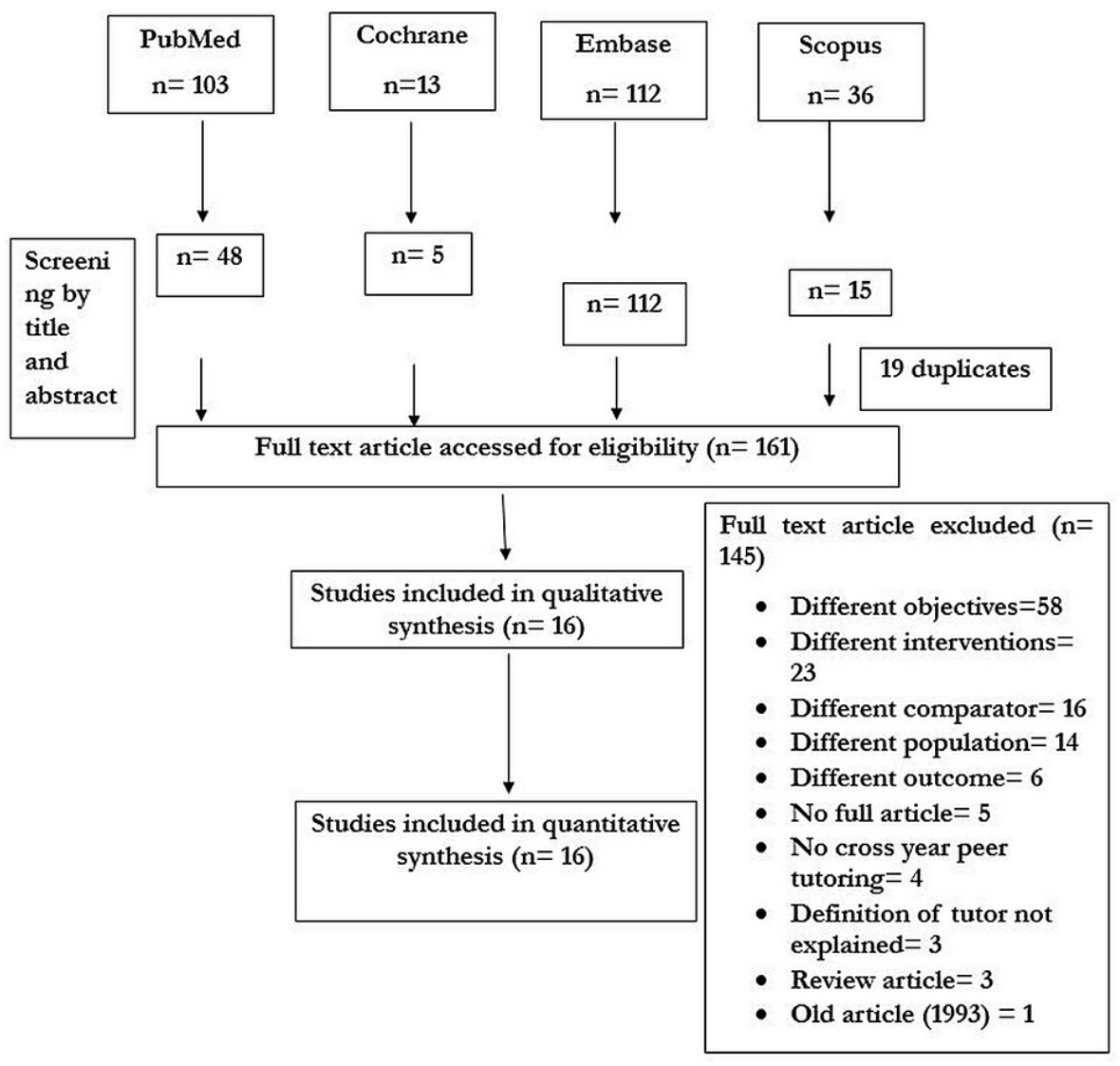

FIGURE 1: PRISMA flow chart of study selection process

PRISMA: Preferred Reporting Items for Systematic Reviews and Meta-Analyses

Characteristics of Sources of Evidence

The characteristics of all included studies are summarized in Table 2. Medical sciences students were the study population in all included studies except three where one study included dental students [11], one nursing [12], and one sports medicine (physiotherapy) [13]. All included studies were randomized experimental designs except one study [14]. In the study by Cameroon et al., though mentioned clusterrandomized trial, the unit of study was an individual student [11]. In the study by Beck et al., historical control of the previous year was enrolled [15]. As per inclusion criteria, the near-peer tutor was defined as one or more years senior to the trainee on the same level of health education training comprising junior residents (senior near-peer) and students (junior near-peer). In seven studies, the near-peer were volunteers [11,14,16-18]. Only in research done by Heckmann et al., peers were trained [19]. All the studies compared teaching by experts and faculty members except in a study done by Graziano, where senior resident (Master of Surgery) was in the comparator group [20]. The teaching-learning method was the same in both study groups except in Beck et al., where the intervention group received small-group teaching and the comparator group received large group teaching [15]. Teaching was conducted via a simulation laboratory in Adam et al. [14] and Graziano [20] and a laboratory setting in Weidner and Popp [13] and Weyrich et al. [21]. In a study done by Adam et al. and Heckmann et al., students' skill and satisfaction were assessed, while in other studies, either knowledge and skill were assessed with or without satisfaction [14,19].

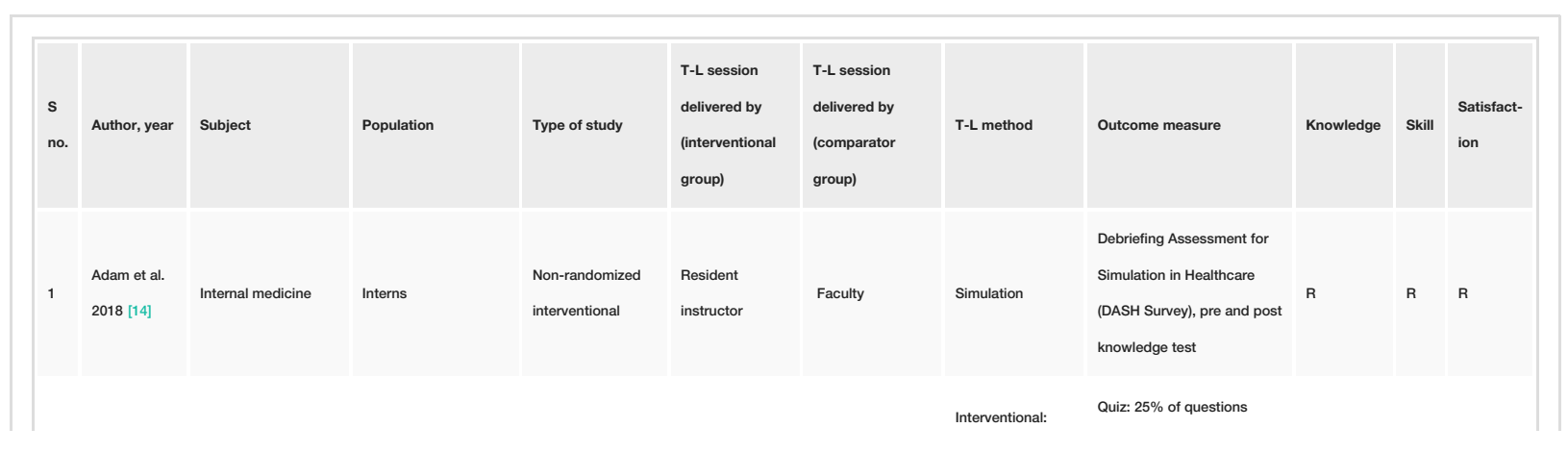




\section{Cureus}

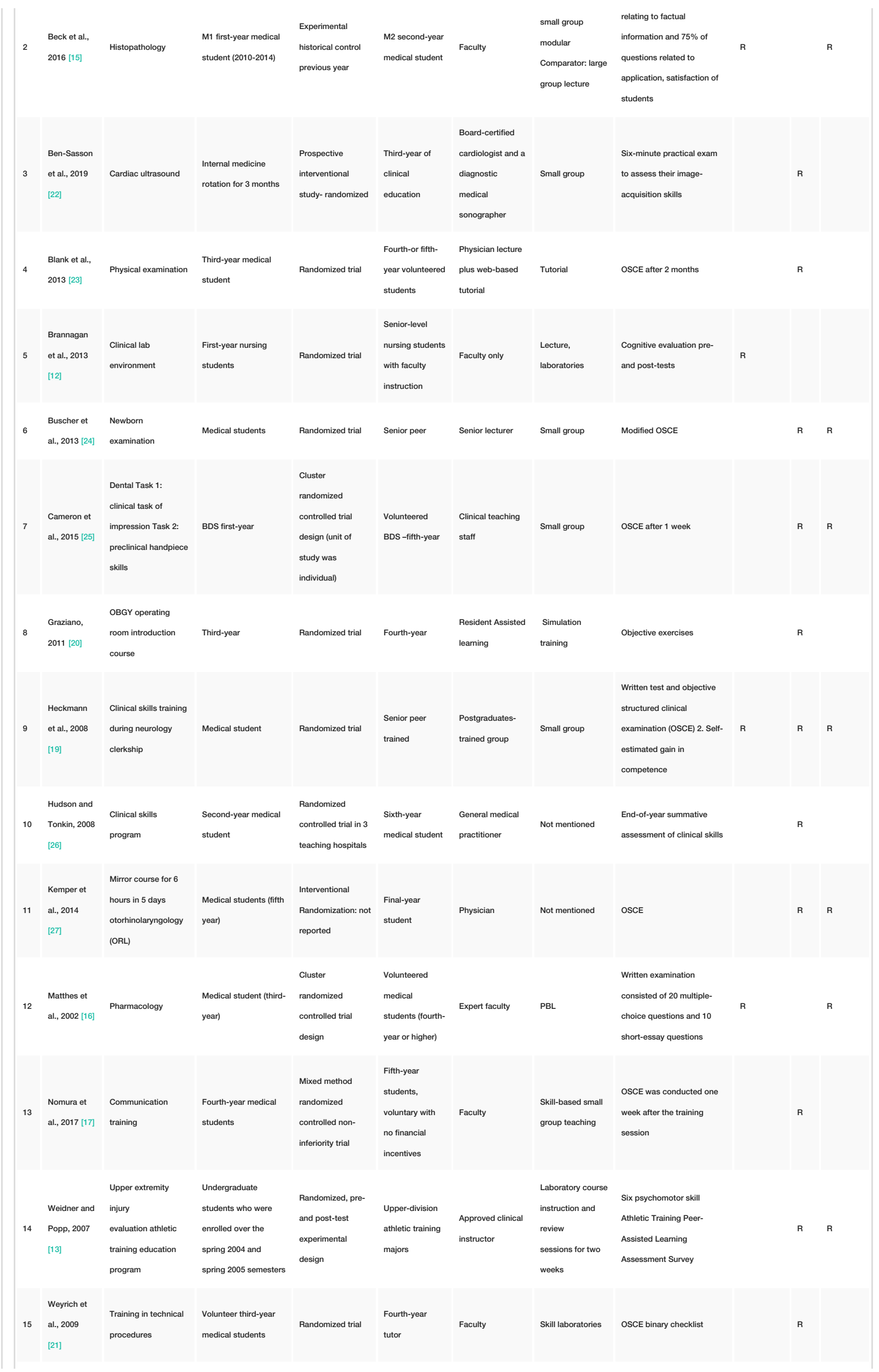




\section{Cureus}

Widyahening Critical appraisal

16 et al., 2019 skills learning

Fourth-year medical Randomized Voluntary near- Experienced

peer tutors medical staff

Tutorials

Evidence-based practice

[18] program

students

crossover tria

medical staff

confidence scale, written R

test, attitude

\section{TABLE 2: Characteristics of included studies}

T-L: teaching-learning; OSCE: objective structured clinical examination; R: reported; BDS: Bachelor of Dental Surgery; PBL: problem-based learning

Quality Assessment of Study

Table 3 shows the study quality assessed with MERSQ1. The score ranged from 10.5 to 14.5 , with a mean of 12.5 (1.095) and a median of 12.5. None of the studies scored below the predetermined cut-off level of 10.5\%. A study carried out in three teaching hospitals scored highest for methodological quality [26]. A study done by Blank had a response rate of less than 50\% [23]. Five studies scored zero under the heading validity of the evaluation instrument as studies did not mention the statement on the content of instrument and validity. None of the included studies studied long-term outcomes in terms of patient benefit. 


\section{Cureus}

\begin{tabular}{|c|c|c|c|c|c|c|c|c|}
\hline $\begin{array}{l}\text { Sr } \\
\text { no }\end{array}$ & Author, year & $\begin{array}{l}\text { Study } \\
\text { design }\end{array}$ & Sampling & $\begin{array}{l}\text { Type of } \\
\text { data }\end{array}$ & $\begin{array}{l}\text { Validity of evaluation } \\
\text { instrument }\end{array}$ & $\begin{array}{l}\text { Data } \\
\text { analysis }\end{array}$ & Outcome & Total \\
\hline 1 & Adam et al., 2018 [14] & 2 & 2 & 3 & 1 & 3 & 1.5 & 12.5 \\
\hline 2 & Beck et al., 2016 [15] & 2 & 2 & 3 & 1 & 3 & 1.5 & 12.5 \\
\hline 3 & $\begin{array}{l}\text { Ben-Sasson et al., } \\
2019 \text { [22] }\end{array}$ & 3 & 1 & 3 & 0 & 2 & 1.5 & 10.5 \\
\hline 4 & Blank et al., 2013 [23] & 3 & $\begin{array}{l}1 \text { (response rate } \\
<50 \%)\end{array}$ & 3 & 1 & 3 & 1.5 & 12.5 \\
\hline 5 & $\begin{array}{l}\text { Brannagan et al., } 2013 \\
\text { [12] }\end{array}$ & 2 & 1 & 3 & 1 & 3 & 1.5 & 11.5 \\
\hline 6 & $\begin{array}{l}\text { Buscher et al., } 2013 \\
\text { [24] }\end{array}$ & 3 & 2 & 3 & 0 & 3 & 1.5 & 12.5 \\
\hline 7 & $\begin{array}{l}\text { Cameron et al., } 2015 \\
\text { [25] }\end{array}$ & 3 & 2 & 3 & 1 & 3 & 1.5 & 13.5 \\
\hline 8 & Graziano, 2011 [20] & 3 & 2.5 & 3 & 2 & 2 & 1.5 & 14 \\
\hline 9 & $\begin{array}{l}\text { Heckmann et al., } 2008 \\
\text { [19] }\end{array}$ & 3 & 1 & 3 & 0 & 2 & 1.5 & 10.5 \\
\hline 10 & $\begin{array}{l}\text { Hudson and Tonkin, } \\
2008 \text { [26] }\end{array}$ & 3 & 3 & 3 & 1 & 3 & 1.5 & 14.5 \\
\hline 11 & $\begin{array}{l}\text { Kemper et al., } 2014 \\
{[27]}\end{array}$ & 2 & 2 & 3 & 1 & 3 & 1.5 & 12.5 \\
\hline 12 & $\begin{array}{l}\text { Matthes et al., } 2002 \\
\text { [16] }\end{array}$ & 3 & 2 & 3 & 0 & 3 & 1.5 & 12.5 \\
\hline 13 & $\begin{array}{l}\text { Nomura et al., } 2017 \\
\text { [17] }\end{array}$ & 3 & 2 & 3 & 0 & 3 & 1.5 & 12.5 \\
\hline 14 & $\begin{array}{l}\text { Weidner and Popp, } \\
2007 \text { [13] }\end{array}$ & 3 & 2 & 3 & 1 & 3 & 1.5 & 13.5 \\
\hline 15 & $\begin{array}{l}\text { Weyrich et al., } 2009 \\
\text { [21] }\end{array}$ & 3 & 2 & 3 & 1 & 3 & 1.5 & 13.5 \\
\hline \multirow[t]{3}{*}{16} & $\begin{array}{l}\text { Widyahening et al., } \\
2019\end{array}$ & 3 & 2 & 3 & 2 & 3 & 1.5 & 14.5 \\
\hline & & \multicolumn{6}{|l|}{ Mean (SD) } & $\begin{array}{l}12.5 \\
(1.095)\end{array}$ \\
\hline & & \multicolumn{6}{|l|}{ Median } & 12.5 \\
\hline
\end{tabular}

TABLE 3: Study quality assessed with MERSQI

MERSQI: Medical Education Research Quality Instrument

Results of Individual Sources of Evidence

Reviewers input post-test scores of all included studies in the current metanalysis as they could not find differences in baseline scores among near-peer and expert groups.

Knowledge: Forest plot of the student's knowledge score with six studies (sample size of 1206 in near-peer and 628 in expert teaching group) shows no difference in effect size $0.08(-0.19,0.34)$ (Figure 2$)$. The heterogeneity ( $\mathrm{I}^{2}$ statistic) was $80 \%$ in fixed-effect model that remained unchanged in the random-effect model. Sensitivity analysis after dropping the study done by Beck et al. as MERSQI score was lowest, i.e., 10.5 , heterogeneity decreased to $58 \%$, no difference in knowledge score was found (Figure 3). 


\begin{tabular}{|c|c|c|c|c|c|c|c|c|c|}
\hline \multirow[b]{2}{*}{ Study or Subgroup } & \multicolumn{3}{|c|}{ near peer } & \multicolumn{3}{|c|}{ expert } & \multicolumn{2}{|c|}{ Std. Mean Difference } & \multirow{2}{*}{$\begin{array}{l}\text { Std. Mean Difference } \\
\text { IV, Random, } 95 \% \mathrm{Cl}\end{array}$} \\
\hline & Mean & SD & Total & Mean & SD & Total & Weight & IV, Random, $95 \% \mathrm{Cl}$ & \\
\hline Adams 2018 & 76.76 & 12.3 & 49 & 81.4 & 17.62 & 49 & $14.5 \%$ & $-0.30[-0.70,0.10]$ & \\
\hline Beck 2016 & 95.2 & 4.9 & 840 & 92.9 & 5.7 & 165 & $19.8 \%$ & $0.46[0.29,0.62]$ & $\pi$ \\
\hline Brannagan 2013 & 6.24 & 1.18 & 120 & 6.22 & 1.42 & 60 & $16.6 \%$ & $0.02[-0.29,0.33]$ & \\
\hline Heckmann 2008 & 69.5 & 10.2 & 66 & 66.7 & 11.4 & 56 & $15.4 \%$ & $0.26[-0.10,0.62]$ & \\
\hline Matthes 2002 & 22.4 & 1.1 & 44 & 23.2 & 2.9 & 144 & $15.9 \%$ & $-0.31[-0.65,0.03]$ & \\
\hline Widyahening 2019 & 65.89 & 12.86 & 87 & 63.18 & 13.69 & 154 & $17.7 \%$ & $0.20[-0.06,0.47]$ & \\
\hline Total $(95 \% \mathrm{Cl})$ & & & 1206 & & & 628 & $100.0 \%$ & $0.08[-0.19,0.34]$ & \\
\hline $\begin{array}{l}\text { Heterogeneity: } \mathrm{Tau}^{2} \\
\text { Test for overall effect: }\end{array}$ & $\begin{array}{l}.08 ; C h \\
=0.56\end{array}$ & $\begin{array}{l}i^{2}=25 \\
(P=0 .\end{array}$ & $\begin{array}{l}08, \mathrm{df}= \\
57)\end{array}$ & & & & & & $\begin{array}{ccccc}1 & 1 & 1 & 1 & 1 \\
-1 & -0.5 & 0 & 0.5 & 1 \\
\text { Favour[Expert] } & \text { Favour [peer] }\end{array}$ \\
\hline
\end{tabular}

FIGURE 2: Forest plot of student's knowledge score in near-peer and expert teaching groups

\begin{tabular}{|c|c|c|c|c|c|c|c|c|c|}
\hline \multirow[b]{2}{*}{ Study or Subgroup } & \multicolumn{3}{|c|}{ near peer } & \multicolumn{2}{|c|}{ expert } & \multirow[b]{2}{*}{ Total } & \multirow{2}{*}{ Weight } & \multirow{2}{*}{$\begin{array}{l}\text { Std. Mean Difference } \\
\text { IV, Random, } 95 \% \mathrm{Cl}\end{array}$} & \multirow{2}{*}{$\begin{array}{r}\text { Std. Mean Difference } \\
\text { IV, Random, } 95 \% \mathrm{Cl}\end{array}$} \\
\hline & Mean & SD & Total & Mean & SD & & & & \\
\hline Adams 2018 & 76.76 & 12.3 & 49 & 81.4 & 17.62 & 49 & $16.8 \%$ & $-0.30[-0.70,0.10]$ & \\
\hline Beck 2016 & 95.2 & 4.9 & 840 & 92.9 & 5.7 & 165 & $0.0 \%$ & $0.46[0.29,0.62]$ & \\
\hline Brannagan 2013 & 6.24 & 1.18 & 120 & 6.22 & 1.42 & 60 & $21.1 \%$ & $0.02[-0.29,0.33]$ & - \\
\hline Heckmann 2008 & 69.5 & 10.2 & 66 & 66.7 & 11.4 & 56 & $18.7 \%$ & $0.26[-0.10,0.62]$ & \\
\hline Matthes 2002 & 22.4 & 1.1 & 44 & 23.2 & 2.9 & 144 & $19.6 \%$ & $-0.31[-0.65,0.03]$ & \\
\hline Widyahening 2019 & 65.89 & 12.86 & 87 & 63.18 & 13.69 & 154 & $23.7 \%$ & $0.20[-0.06,0.47]$ & \\
\hline Total $(95 \% \mathrm{Cl})$ & & & 366 & & & 463 & $100.0 \%$ & $-0.01[-0.24,0.22]$ & \\
\hline \multicolumn{7}{|c|}{$\begin{array}{l}\text { Heterogeneity: } \mathrm{Tau}^{2}=0.04 ; \mathrm{Ch}^{2}=9.61, \mathrm{df}=4(\mathrm{P}=0.05) ; \mathrm{I}^{2}=58 \% \\
\text { Test for overall effect: } Z=0.10(P=0.92)\end{array}$} & & & $\begin{array}{ccccc}1 & 1 & 1 & 1 & 1 \\
-1 & -0.5 & 0 & 0.5 & 1 \\
\text { Favour[Expert] } & \text { Favour [peer] }\end{array}$ \\
\hline
\end{tabular}

FIGURE 3: Sensitivity analysis forest plot of student's knowledge score in near-peer and expert teaching groups

Skill: In Figure 4, when 10 studies were included, the $\mathrm{I}^{2}$ statistic was $85 \%$ and the estimate was imprecise ($0.13,0.56)$. Heterogeneity remained unchanged in the random-effect model. The total sample size was 551 in the intervention group (near-peer) and 497 in the expert group. The study done by Blank et al. favored the near-peer with standardized mean difference (SMD) of 6.73 (4.8-8.66) [23]. We excluded the study done by Blank et al. because the response rate was less than $50 \%$, so the study result might not be reliable. Figure 5 shows no difference in skill score in near-peer and expert teaching groups, $\mathrm{I}^{2}$ statistic decreased to $42 \%$.

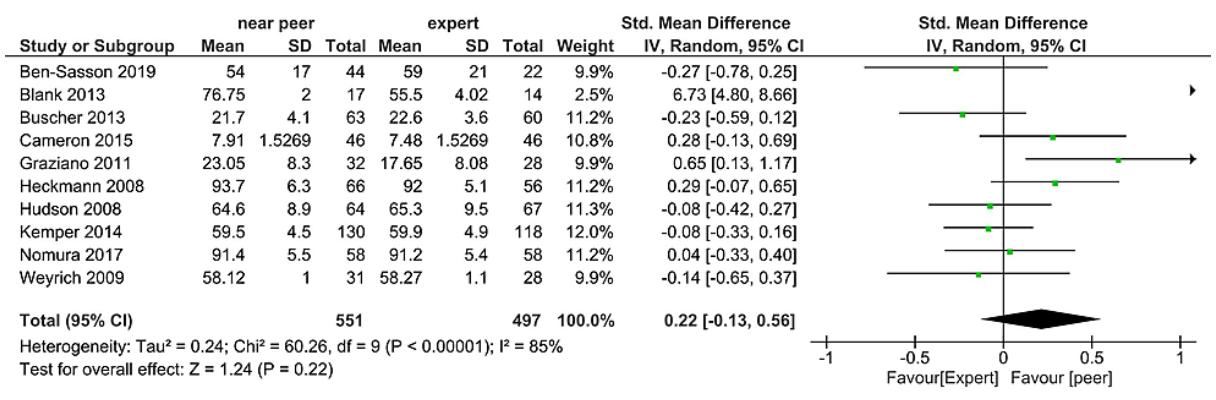

FIGURE 4: Forest plot of student's skill score in near-peer and expert teaching groups 


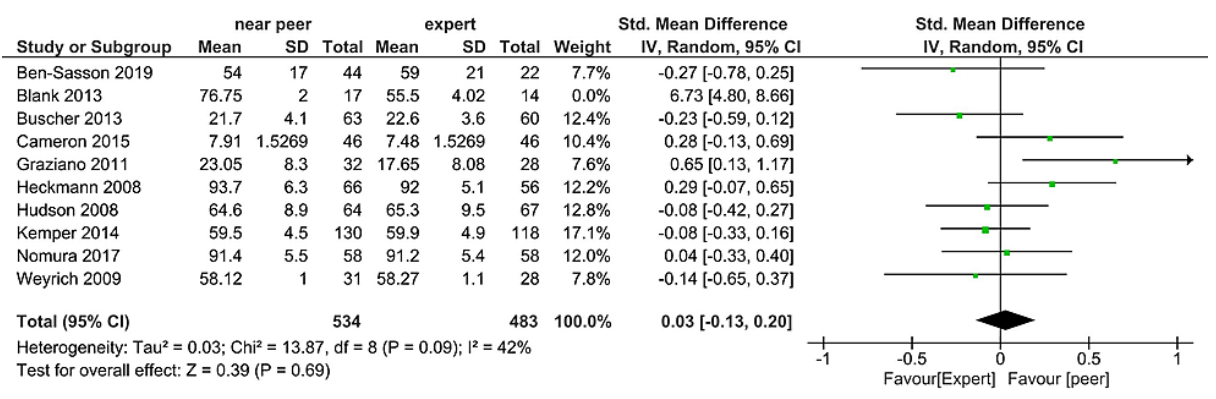

\section{FIGURE 5: Sensitivity analysis forest plot of student's skill score in near-peer and expert teaching groups}

Satisfaction: Eight included studies conducted satisfaction surveys among the learners for perceived satisfaction, opinion, experiences, or learning effect. These surveys were in the form of using Debriefing assessment survey or evidence-based practice score, Likert scale or yes/no, agree/disagree dichotomous type questions Kemper found improved perceived learning effect [27]. Other studies showed that a higher proportion of students were satisfied as it was stimulating [20] and less anxious, felt more confident, and enhance collaborative skills [13]. Satisfaction survey scores among the near-peer teaching and expert teaching were found to be non-significant $[14,16,18]$.

Perceived benefits: The benefits are mentioned for peer tutors, learners, and administrators. Peer tutor's benefits were developed teaching, communication, coordination, mentorship, and time management skills. Peer tutors had the opportunity for a deeper understanding of the taught subject. Students felt more comfortable with peers who were approachable and well aware of student level of understanding. The learning environment was of comparably low threat and informal. An overall student gave positive feedback for near-peer teaching. In terms of administration, peer teaching not hindered daily ward rounds, a large number of students were trained simultaneously (Figure o).

- Development of teaching, communication, coordination, mentorship, and time management skills.

- Peers are more aware of student's level of understanding.

- Provision of an informal and comparably low threat learning environment.

- Large number of students are simultaneously trained.

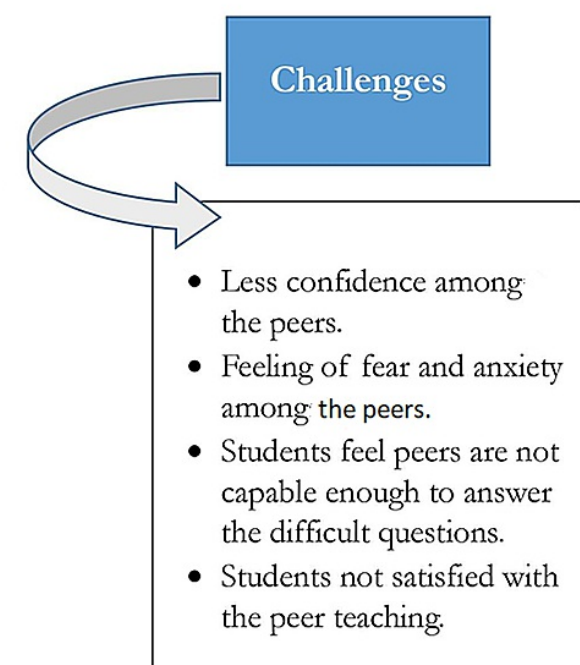

\section{Benefits}

FIGURE 6: Benefits and challenges of near-peer teaching

Perceived challenges: The authors had also encountered some challenges like some of the studentexpressed dissatisfaction with peer teaching. They felt peers were not trained and not compatible to handle the difficult questions posed by students. Peer tutors themselves felt anxiety and not confident in teaching. 
In many studies, peers did not teach voluntarily but were forced due to curriculum structure.

\section{Discussion}

Summary of Evidence

The main finding of the present systematic review was the absence of any significant difference between the near-peer teaching and expert teaching groups in terms of knowledge and skill scores. Studies on comparison of near-peer and expert were existing but with small sample sizes. The present study is the only study to the best of our knowledge where meta-analysis is conducted for the effectiveness of near-peer teaching. Our review's result is in line with a 15-year literature review of peer-led basic life support (BLS) course that demonstrated excellent learning outcomes, cost-effectiveness compared to experts, and peers were more approachable [28]. Near-peer tutoring programs like student grand round, Acute Care Skills Training (ACST) course, and Clinical Skills and Simulation course were found to be effective in enhancing the knowledge and skills of both near-peer and students and were well-received by students [29-31].

Even though the methodological quality of included studies was good, we found considerable heterogeneity in knowledge score, which may be due to different settings, programs, populations, and characteristics of near-peers. A study by Beck et al. was done with a historical cohort of the previous four years as control [15]. This time frame may be a source of heterogeneity and when the study was removed from the meta-analysis of knowledge score, it resulted in moderate heterogeneity of $58 \%$. Similarly, for skill scores, the heterogeneity was considerable remained unexplained by the random effect model. The study by Blank et al. was omitted from analysis due to a response rate of less than $50 \%$, which means maybe the only student who was well-prepared may have appeared in the assessment [23]. Though the study mentioned non-response rate was the same in both the study group, the final result may be biased. The forest plot of skill scores on sensitivity analysis also showed no difference in skill scores in both study groups with moderate heterogeneity. The satisfaction of students in our review is in line with Liew et al. that demonstrated consistently higher scores in near-peer evaluation by a large number of students ( $\mathrm{n}=985)$, suggesting that students benefited from near-peer teaching sessions [31].

Volunteered peers participated in two of the included studies [23,25]. The volunteer nature of these programs may have drawn motivated peer tutors and may have a comparable higher score in peer-group than the expert. Wadoodi and Crosby also highlighted that near-peer voluntary recruitment creates an opportunity for participation from potential peers motivated to teach [32]. Near-peers were trained in only one study, which was considered a limitation and challenge in other studies [19]. Training will further improve performance, confidence, decrease anxiety, and role clarity among near-peer tutors.

Near-peer teaching mutually benefits both tutor and tutee. In our included studies, tutors felt that they could revisit previously learned topics while refining key proficiencies required by different health graduates, such as teaching skills, time management, and leadership. The tutee had also been benefited from advice from previously successful students with first-hand experience in their exams, teaching done at an appropriate level, and a comfortable and safe learning environment. This confirms the hypothesis "cognitive congruence" given by Lockspeiser et al. [33]. However, the authors of included studies encountered various challenges regarding administration (sustainability of program), untrained, incompetent peers. Standardization in the quality of teaching by different peers should be ensured. We further believe that if a near-peer program is initiated as per tips given by Wadoodi and Crosby on tutor selection, training the tutor, and running and evaluating the sessions will further make near-peer a valuable source for medical colleges [30,34].

Limitations: Reviewers could not ascertain the reporting bias due to fewer studies. Full article could not be retrieved in five studies, and few studies did not clarify the qualification of peer in comparison to study participants. This review only included the studies in the English language, which means that the studies published in another language were not analyzed. There is always a possibility that the systematic search did not acquire all relevant literature as per inclusion criteria.

\section{Conclusions}

There was no significant difference in knowledge and skill scores among students taught by near-peers compared to faculty/expert. Overall, students were satisfied with the near-peers teaching skill and their ability to create a comfortable learning environment. As the process of near-peer teaching benefits tutor, tutee, and administrator (due to limited faculty members), peer teaching should be strengthened by orienting students to basic medical education technology in early medical and hand-holding interested students to develop their teaching-learning skills further. Near-peer programs should be part of curriculum delivery right from students entering the health education field to post-graduate trainees.

\section{Appendices}




\section{Cureus}

\begin{tabular}{|c|c|c|c|}
\hline $\begin{array}{l}\text { Section and } \\
\text { topic }\end{array}$ & $\begin{array}{l}\text { Item } \\
\#\end{array}$ & Checklist item & $\begin{array}{l}\text { Location } \\
\text { where } \\
\text { item is } \\
\text { reported }\end{array}$ \\
\hline \multicolumn{4}{|l|}{ Title } \\
\hline Title & 1 & Identify the report as a systematic review. & $\operatorname{Pg} 1$ \\
\hline \multicolumn{4}{|l|}{ Abstract } \\
\hline Abstract & 2 & See the PRISMA 2020 for Abstracts checklist. & $\mathrm{Pg} 2$ \\
\hline \multicolumn{4}{|l|}{ Introduction } \\
\hline Rationale & 3 & Describe the rationale for the review in the context of existing knowledge. & $\mathrm{Pg} 3$ \\
\hline Objectives & 4 & Provide an explicit statement of the objective(s) or question(s) the review addresses. & $\mathrm{Pg} 3$ \\
\hline \multicolumn{4}{|l|}{ Methods } \\
\hline $\begin{array}{l}\text { Eligibility } \\
\text { criteria }\end{array}$ & 5 & $\begin{array}{l}\text { Specify the inclusion and exclusion criteria for the review and how studies were grouped for } \\
\text { the syntheses. }\end{array}$ & $\operatorname{Pg} 4$ \\
\hline $\begin{array}{l}\text { Information } \\
\text { sources }\end{array}$ & 6 & $\begin{array}{l}\text { Specify all databases, registers, websites, organizations, reference lists, and other sources } \\
\text { searched or consulted to identify studies. Specify the date when each source was last } \\
\text { searched or consulted. }\end{array}$ & $\operatorname{Pg} 5$ \\
\hline $\begin{array}{l}\text { Search } \\
\text { strategy }\end{array}$ & 7 & $\begin{array}{l}\text { Present the full search strategies for all databases, registers, and websites, including any } \\
\text { filters and limits used. }\end{array}$ & $\operatorname{Pg} 5$ \\
\hline $\begin{array}{l}\text { Selection } \\
\text { process }\end{array}$ & 8 & $\begin{array}{l}\text { Specify the methods used to decide whether a study met the inclusion criteria of the review, } \\
\text { including how many reviewers screened each record and each report retrieved, whether they } \\
\text { worked independently, and if applicable, details of automation tools used in the process. }\end{array}$ & $\operatorname{Pg} 6$ \\
\hline $\begin{array}{l}\text { Data } \\
\text { collection } \\
\text { process }\end{array}$ & 9 & $\begin{array}{l}\text { Specify the methods used to collect data from reports, including how many reviewers } \\
\text { collected data from each report, whether they worked independently, any processes for } \\
\text { obtaining or confirming data from study investigators, and if applicable, details of automation } \\
\text { tools used in the process. }\end{array}$ & $\operatorname{Pg} 6$ \\
\hline \multirow{2}{*}{ Data items } & $10 \mathrm{a}$ & $\begin{array}{l}\text { List and define all outcomes for which data were sought. Specify whether all results that were } \\
\text { compatible with each outcome domain in each study were sought (e.g. for all measures, time } \\
\text { points, analyses), and if not, the methods used to decide which results to collect. }\end{array}$ & $\operatorname{Pg} 7$ \\
\hline & $10 \mathrm{~b}$ & $\begin{array}{l}\text { List and define all other variables for which data were sought (e.g. participant and } \\
\text { intervention characteristics, funding sources). Describe any assumptions made about any } \\
\text { missing or unclear information. }\end{array}$ & \\
\hline $\begin{array}{l}\text { Study risk of } \\
\text { bias } \\
\text { assessment }\end{array}$ & 11 & $\begin{array}{l}\text { Specify the methods used to assess risk of bias in the included studies, including details of } \\
\text { the tool(s) used, how many reviewers assessed each study and whether they worked } \\
\text { independently, and if applicable, details of automation tools used in the process. }\end{array}$ & $\operatorname{Pg} 7$ \\
\hline $\begin{array}{l}\text { Effect } \\
\text { measures }\end{array}$ & 12 & $\begin{array}{l}\text { Specify for each outcome the effect measure(s) (e.g. risk ratio, mean difference) used in the } \\
\text { synthesis or presentation of results. }\end{array}$ & $\operatorname{Pg} 7$ \\
\hline \multirow{6}{*}{$\begin{array}{l}\text { Synthesis } \\
\text { methods }\end{array}$} & $13 a$ & $\begin{array}{l}\text { Describe the processes used to decide which studies were eligible for each synthesis (e.g. } \\
\text { tabulating the study intervention characteristics and comparing against the planned groups } \\
\text { for each synthesis (item \#5)). }\end{array}$ & $\operatorname{Pg} 7$ \\
\hline & $13 b$ & $\begin{array}{l}\text { Describe any methods required to prepare the data for presentation or synthesis, such as } \\
\text { handling of missing summary statistics, or data conversions. }\end{array}$ & $\operatorname{Pg} 7$ \\
\hline & $13 c$ & $\begin{array}{l}\text { Describe any methods used to tabulate or visually display results of individual studies and } \\
\text { syntheses. }\end{array}$ & $\operatorname{Pg} 7$ \\
\hline & $13 d$ & $\begin{array}{l}\text { Describe any methods used to synthesize results and provide a rationale for the choice(s). If } \\
\text { meta-analysis was performed, describe the model(s), method(s) to identify the presence and } \\
\text { extent of statistical heterogeneity, and software package(s) used. }\end{array}$ & $\operatorname{Pg} 7$ \\
\hline & $13 e$ & $\begin{array}{l}\text { Describe any methods used to explore possible causes of heterogeneity among study results } \\
\text { (e.g. subgroup analysis, meta-regression). }\end{array}$ & $\operatorname{Pg} 7$ \\
\hline & & & \\
\hline
\end{tabular}




\section{Cureus}

\begin{tabular}{|c|c|c|c|}
\hline $\begin{array}{l}\text { Reporting bias } \\
\text { Sectionnand } \\
\text { aegriesment } \\
\text { Certainty } \\
\text { assessment }\end{array}$ & $\begin{array}{l}\text { 14tem } \\
\#\end{array}$ & $\begin{array}{l}\text { Describe any methods used to assess risk of bias due to missing results in a synthesis } \\
\text { (anthistritemporting biases). } \\
\text { Describe any methods used to assess certainty (or confidence) in the body of evidence for an } \\
\text { outcome. }\end{array}$ & $\begin{array}{l}\text { Location } \\
\text { Puglvere } \\
\text { item is } \\
\text { reported } \\
\text { Not done }\end{array}$ \\
\hline \multicolumn{4}{|l|}{ Results } \\
\hline \multirow{2}{*}{$\begin{array}{l}\text { Study } \\
\text { selection }\end{array}$} & $16 \mathrm{a}$ & $\begin{array}{l}\text { Describe the results of the search and selection process, from the number of records } \\
\text { identified in the search to the number of studies included in the review, ideally using a flow } \\
\text { diagram. }\end{array}$ & $\operatorname{Pg} 7-8$ \\
\hline & $16 \mathrm{~b}$ & $\begin{array}{l}\text { Cite studies that might appear to meet the inclusion criteria, but which were excluded, and } \\
\text { explain why they were excluded. }\end{array}$ & $\operatorname{Pg} 7-8$ \\
\hline $\begin{array}{l}\text { Study } \\
\text { characteristics }\end{array}$ & 17 & Cite each included study and present its characteristics. & $\operatorname{Pg} 10-14$ \\
\hline $\begin{array}{l}\text { Risk of bias in } \\
\text { studies }\end{array}$ & 18 & Present assessments of risk of bias for each included study. & $\operatorname{Pg} 15$ \\
\hline $\begin{array}{l}\text { Results of } \\
\text { individual } \\
\text { studies }\end{array}$ & 19 & $\begin{array}{l}\text { For all outcomes, present, for each study: (a) summary statistics for each group (where } \\
\text { appropriate) and (b) an effect estimate and its precision (e.g. confidence/credible interval), } \\
\text { ideally using structured tables or plots. }\end{array}$ & $\begin{array}{l}\operatorname{Pg} 16 \text { and } \\
17\end{array}$ \\
\hline \multirow{4}{*}{$\begin{array}{l}\text { Results of } \\
\text { syntheses }\end{array}$} & $20 \mathrm{a}$ & $\begin{array}{l}\text { For each synthesis, briefly summarise the characteristics and risk of bias among contributing } \\
\text { studies. }\end{array}$ & $\begin{array}{l}\mathrm{Pg} 16 \text { and } \\
17\end{array}$ \\
\hline & 20b & $\begin{array}{l}\text { Present results of all statistical syntheses conducted. If meta-analysis was done, present for } \\
\text { each the summary estimate and its precision (e.g. confidence/credible interval) and measures } \\
\text { of statistical heterogeneity. If comparing groups, describe the direction of the effect. }\end{array}$ & $\begin{array}{l}\operatorname{Pg} 16 \text { and } \\
17\end{array}$ \\
\hline & $20 \mathrm{c}$ & Present results of all investigations of possible causes of heterogeneity among study results. & $\begin{array}{l}\mathrm{Pg} 16 \text { and } \\
17\end{array}$ \\
\hline & 20d & $\begin{array}{l}\text { Present results of all sensitivity analyses conducted to assess the robustness of the } \\
\text { synthesized results. }\end{array}$ & $\begin{array}{l}\operatorname{Pg} 16 \text { and } \\
17\end{array}$ \\
\hline $\begin{array}{l}\text { Reporting } \\
\text { biases }\end{array}$ & 21 & $\begin{array}{l}\text { Present assessments of risk of bias due to missing results (arising from reporting biases) for } \\
\text { each synthesis assessed. }\end{array}$ & $\begin{array}{l}\mathrm{Pg} 16 \text { and } \\
17\end{array}$ \\
\hline $\begin{array}{l}\text { Certainty of } \\
\text { evidence }\end{array}$ & 22 & $\begin{array}{l}\text { Present assessments of certainty (or confidence) in the body of evidence for each outcome } \\
\text { assessed. }\end{array}$ & $\begin{array}{l}\mathrm{Pg} 16 \text { and } \\
17\end{array}$ \\
\hline \multicolumn{4}{|l|}{ Discussion } \\
\hline \multirow{4}{*}{ Discussion } & 23a & Provide a general interpretation of the results in the context of other evidence. & $\operatorname{Pg} 19$ \\
\hline & 23b & Discuss any limitations of the evidence included in the review. & $\mathrm{Pg} 20$ \\
\hline & $23 c$ & Discuss any limitations of the review processes used. & $\mathrm{Pg} 20$ \\
\hline & 23d & Discuss implications of the results for practice, policy, and future research. & $\mathrm{Pg} 20$ \\
\hline \multicolumn{4}{|c|}{ Other information } \\
\hline \multirow{3}{*}{$\begin{array}{l}\text { Registration } \\
\text { and protocol }\end{array}$} & $24 a$ & $\begin{array}{l}\text { Provide registration information for the review, including register name and registration } \\
\text { number, or state that the review was not registered. }\end{array}$ & $\begin{array}{l}\text { Not } \\
\text { registered }\end{array}$ \\
\hline & $24 \mathrm{~b}$ & $\begin{array}{l}\text { Indicate where the review protocol can be accessed, or state that a protocol was not } \\
\text { prepared. }\end{array}$ & $\begin{array}{l}\text { Protocol } \\
\text { was } \\
\text { prepared }\end{array}$ \\
\hline & $24 c$ & $\begin{array}{l}\text { Describe and explain any amendments to information provided at registration or in the } \\
\text { protocol. }\end{array}$ & None \\
\hline Support & 25 & $\begin{array}{l}\text { Describe sources of financial or non-financial support for the review, and the role of the } \\
\text { funders or sponsors in the review. }\end{array}$ & $\operatorname{Pg} 21$ \\
\hline $\begin{array}{l}\text { Competing } \\
\text { interests }\end{array}$ & 26 & Declare any competing interests of review authors. & Pg 21 \\
\hline
\end{tabular}

Availability of

Report which of the following are publicly available and where they can be found: template 


\section{Cureus}

data, code, 27 data collection forms; data extracted from included studies; data used for all analyses; asdcitbar and Item analytic code; any other materials used in the review. ntapifials \# Checklist item

\section{TABLE 4: PRISMA 2020 checklist}

PRISMA: Preferred Reporting Items for Systematic Reviews and Meta-Analyses

\section{Additional Information \\ Disclosures}

Conflicts of interest: In compliance with the ICMJE uniform disclosure form, all authors declare the following: Payment/services info: All authors have declared that no financial support was received from any organization for the submitted work. Financial relationships: All authors have declared that they have no financial relationships at present or within the previous three years with any organizations that might have an interest in the submitted work. Other relationships: All authors have declared that there are no other relationships or activities that could appear to have influenced the submitted work.

\section{References}

1. Lim SY, Koh EY, Tan BJ, Toh YP, Mason S, Krishna LK: Enhancing geriatric oncology training through a combination of novice mentoring and peer and near-peer mentoring: a thematic analysis of mentoring in medicine between 2000 and 2017. J Geriatr Oncol. 2020, 11:566-75. 10.1016/j.jgo.2019.09.008

2. Akinla O, Hagan P, Atiomo W: A systematic review of the literature describing the outcomes of near-peer mentoring programs for first year medical students. BMC Med Educ. 2018, 18:98. 10.1186/s12909-018-11951

3. Singh S, Singh N, Dhaliwal U: Near-peer mentoring to complement faculty mentoring of first-year medical students in India. J Educ Eval Health Prof. 2014, 30:11.

4. Hundertmark J, Alvarez S, Loukanova S, Schultz JH: Stress and stressors of medical student near-peer tutors during courses: a psychophysiological mixed methods study. BMC Med Educ. 2019, 19:95. 10.1186/s12909019-1521-2

5. Rees EL, Quinn PJ, Davies B, Fotheringham V: How does peer teaching compare to faculty teaching? A systematic review and meta-analysis (.). Med Teach. 2016, 38:829-37. 10.3109/0142159X.2015.1112888

6. Page MJ, McKenzie JE, Bossuyt PM, et al.: The PRISMA 2020 statement: an updated guideline for reporting systematic reviews. BMJ. 2021, 372:n71. 10.1136/bmj.n71

7. Bulte C, Betts A, Garner K, Durning S: Student teaching: views of student near-peer teachers and learners . Med Teach. 2007, 29:583-90. 10.1080/01421590701583824

8. Patricia S: The Medical Education Research Study Quality Instrument (MERSQI). 2012 Western Institute of Nursing Annual Communicating Nursing Research Conference. UCLA, Portland, OR; 2011.

9. Cook DA, Reed DA: Appraising the quality of medical education research methods: the Medical Education Research Study Quality Instrument and the Newcastle-Ottawa Scale-Education. Acad Med. 2015, 90:106776. 10.1097/ACM.0000000000000786

10. Reed DA, Beckman TJ, Wright SM, Levine RB, Kern DE, Cook DA: Predictive validity evidence for medical education research study quality instrument scores: quality of submissions to JGIM's Medical Education Special Issue. J Gen Intern Med. 2008, 23:903-7. 10.1007/s11606-008-0664-3

11. Cameron A, Ezzat A, Parson SH, Venkatesh A: The peer-assisted learning scheme: a strategy for improving confidence in anatomical knowledge in final year medical students- "Docendo Discimus". Anatomical Society Winter Conference. University of Aberdeen, Birmingham, UK; 2014.

12. Brannagan KB, Dellinger A, Thomas J, Mitchell D, Lewis-Trabeaux S, Dupre S: Impact of peer teaching on nursing students: perceptions of learning environment, self-efficacy, and knowledge. Nurse Educ Today. 2013, 33:1440-7. 10.1016/j.nedt.2012.11.018

13. Weidner TG, Popp JK: Peer-assisted learning and orthopaedic evaluation psychomotor skills . J Athl Train. 2007, 42:113-9.

14. Adams T, Newton C, Patel H, Sulistio M, Tomlinson A, Lee W: Resident versus faculty member simulation debriefing. Clin Teach. 2018, 15:462-6. 10.1111/tct.12735

15. Beck A, Wood C, Helms R, Arvizo C, Cherry BM, Ziats NP: Peer-assisted learning in introductory histopathology improves learner scores and delivers learner satisfaction. Med Sci Educ. 2016, 26:85-92. 10.1007/s40670-015-0207-6

16. Matthes J, Marxen B, Linke R, et al.: The influence of tutor qualification on the process and outcome of learning in a problem-based course of basic medical pharmacology. Naunyn Schmiedebergs Arch Pharmacol. 2002, 366:58-63. 10.1007/s00210-002-0551-0

17. Nomura O, Onishi H, Kato H: Medical students can teach communication skills - a mixed methods study of cross-year peer tutoring. BMC Med Educ. 2017, 17:103. 10.1186/s12909-017-0939-7

18. Widyahening IS, Findyartini A, Ranakusuma RW, Dewiasty E, Harimurti K: Evaluation of the role of nearpeer teaching in critical appraisal skills learning: a randomised crossover trial. Int J Med Educ. 2019, 2510:915. 10.5116/ijme.5c39.b55b

19. Heckmann JG, Dütsch M, Rauch C, Lang C, Weih M, Schwab S: Effects of peer-assisted training during the neurology clerkship: a randomized controlled study. Eur J Neurol. 2008, 15:1365-70. 10.1111/j.14681331.2008.02317.x

20. Graziano SC: Randomised surgical training for medical students: resident versus peer-led teaching. Am J 
Obstet Gynecol. 2011, 204:1-4. 10.1016/j.ajog.2011.01.038

21. Weyrich P, Celebi N, Schrauth M, Möltner A, Lammerding-Köppel M, Nikendei C: Peer-assisted versus faculty staff-led skills laboratory training: a randomised controlled trial. Med Educ. 2009, 43:113-20. 10.1111/j.1365-2923.2008.03252.x

22. Ben-Sasson A, Lior Y, Krispel J, Rucham M, Liel-Cohen N, Fuchs L, Kobal SL: Peer-teaching cardiac ultrasound among medical students: a real option. PLoS One. 2019, 14: 10.1371/journal.pone.0212794

23. Blank WA, Blankenfeld H, Vogelmann R, Linde K, Schneider A: Can near-peer medical students effectively teach a new curriculum in physical examination?. BMC Med Educ. 2013, 13:165. 10.1186/1472-6920-13-165

24. Büscher R, Weber D, Büscher A, Hölscher M, Pohlhuis S, Groes B, Hoyer PF: Evaluation of the peer teaching program at the University Children's Hospital Essen - a single center experience. GMS Z Med Ausbild. 2013, 30:25. 10.3205/zma000868

25. Cameron DA, Binnie VI, Sherriff A, Bissell V: Peer assisted learning: teaching dental skills and enhancing graduate attributes. Br Dent J. 2015, 219:267-72. 10.1038/sj.bdj.2015.722

26. Hudson JN, Tonkin AL: Clinical skills education: outcomes of relationships between junior medical students, senior peers and simulated patients. Med Educ. 2008, 42:901-8. 10.1111/j.1365-2923.2008.03107.X

27. Kemper M, Linke J, Zahnert T, Neudert M: teaching and peer assessment are appropriate tools in medical education in otorhinolaryngology. [Article in German]. Laryngorhinootologie. 2014, 93:392-7. 10.1055/s0034-1370944

28. Harvey PR, Higenbottam CV, Owen A, Hulme J, Bion JF: Peer-led training and assessment in basic life support for healthcare students: synthesis of literature review and fifteen years practical experience. Resuscitation. 2012, 83:894-9. 10.1016/j.resuscitation.2012.01.013

29. Silbert BI, Lake FR: Peer-assisted learning in teaching clinical examination to junior medical students . Med Teach. 2012, 34:392-7. 10.3109/0142159X.2012.668240

30. Beane A, Padeniya A, De Silva, et al.: Closing the theory to practice gap for newly qualified doctors: evaluation of a peer-delivered practical skills training course for newly qualified doctors in preparation for clinical practice. Postgrad Med J. 2017, 93:592-6. 10.1136/postgradmedj-2016-134718

31. Liew SC, Sow CF, Sidhu J, Nadarajah VD: The near-peer tutoring programme: embracing the 'doctors-toteach' philosophy--a comparison of the effects of participation between the senior and junior near-peer tutors. Med Educ Online. 2015, 20:10.3402/meo.v20.27959

32. Wadoodi A, Crosby JR: Twelve tips for peer-assisted learning: a classic concept revisited . Med Teach. 2002, 24:241-4. 10.1080/01421590220134060

33. Lockspeiser TM, O'Sullivan P, Teherani A, Muller J: Understanding the experience of being taught by peers: the value of social and cognitive congruence. Adv Health Sci Educ. 2008, 13:361-72. 10.1007/s10459-0069049-8

34. Durán CE, Bahena EN, Rodríguez Mde L, Baca GJ, Uresti AS, Elizondo-Omaña RE, López SG: Near-peer teaching in an anatomy course with a low faculty-to-student ratio. Anat Sci Educ. 2012, 5:171-6. 10.1002/ase.1269 